\title{
Climate-based policies may increase life-cycle social costs of vehicle fleet operation
}

Isaac Emery, Eric Mbonimpa, Alfred E. Thal, Jr.

Air Force Institute of Technology (AFIT), Department of Systems Engineering and Management, 2950 Hobson Way, Wright Patterson AFB, OH 45433

Correspondence: Eric Mbonimpa, Assistant Professor, Department of Systems Engineering and Management, Air Force Institute of Technology, 2950 Hobson Way, Wright Patterson AFB, OH 45433. Email: eric.mbonimpa@afit.edu ,Phone: 937-255-3636 (7405)

\footnotetext{
ABSTRACT

Sustainability guidelines and regulations in the United States often focus exclusively on carbon or petroleum reductions. Though some of these policies have resulted in substantial progress toward their goals, the effects of these efforts on other social and environmental externalities are often ignored. In this study, we examine the life-cycle air pollutant emissions for alternative fuel and vehicle purchase scenarios at a military installation near a typical urban area in the United States (U.S.). We find that scenarios which minimize petroleum use or greenhouse gas emissions do not concomitantly minimize criteria air pollutant emissions. We also employ social cost methodologies to quantify economic externalities due to climate change and health-related air pollutant impacts. Accounting for the social costs of climate change and air pollution from vehicle use reveals that criteria air pollutants may have a greater total impact than greenhouse gas emissions in locations similar to the urban area examined in this study. Use of first-generation biofuels, particularly corn grain ethanol, may reduce net petroleum use at the cost of increased total health impacts. More
} 
comprehensive policies may be needed to ensure that sustainability policies result in a net benefit to society.

Keywords: energy policy, social cost, air pollution

Word Count: 6086 


\section{Introduction}

Automotive fuel use represents a substantial fraction of energy-related greenhouse gas emissions globally (20\%) and in the United States (28\%); it also accounts for the majority (69\%) of U.S. petroleum use (EIA, 2013). Major policy interventions, such as the U.S. Renewable Fuels Standard, focus on transportation fuels and vehicles to achieve climate change mitigation and energy security goals. Additionally, the Department of Defense (DoD) has developed internal goals to achieve 30\% reductions in petroleum use by non-tactical vehicles by 2020. The DoD has worked to achieve this goal by eliminating underutilized vehicles and integrating a variety of electric and bio-fuel capable vehicles into military base operations (E.O., 2015; Blakeley, 2012; DOD, 2013, 2014). Although most service branches have exceeded their midpoint goals, Air Force petroleum use in 2013 was 1.7\% higher than 2005 baseline levels despite the acquisition of nearly 10,000 E85 capable vehicles and 2,000 hybrid-electric vehicles (Kendall, 2013).

Vehicle tailpipe emissions are also leading sources of air pollution, notably particulates (PM), ozone $\left(\mathrm{O}_{3}\right)$, and carbon monoxide (CO) (Brinkman et al., 2005; EPA, 2014). Since tailpipe emissions are typically at ground level, exposure rates can be much higher than for other pollution sources, thus leading to an estimated 58,000 early deaths annually in the U.S. (Caiazzo et al., 2013). Because of these impacts and the quantity of fuel consumed in the U.S., the use phase often dominates life-cycle assessments of health and environmental impacts of transportation, including total greenhouse gas emissions (Chester and Horvath, 2009; Hawkins et al., 2013). While the role of internal combustion vehicles in air pollution and the potential of alternative fuels to mitigate greenhouse gas emissions are both widely acknowledged and relatively well understood, current understanding of the potential tradeoffs between these two goals is limited. Although climate change mitigation and energy security policies are generally expected to be compatible with air pollution and health cost 
reductions (McCollum et al., 2013), there is evidence that first-generation alternative fuels such as corn ethanol lead to higher health costs due to air pollution than conventional fuels (Hill et al., 2009).

Methods are now available to determine the costs to society of externalities, such as the health and mortality effects of air pollution, which can be used to assess health, climate, and economic effects on a common basis (Heo, 2015; Krewski et al., 2009; Lepeule et al., 2012). Because these effects are dependent not only on the quantity of pollution emitted but also the population exposed, applying social cost methods to vehicle fleet decision-making requires an understanding of the spatial distribution of feedstock, fuel, and energy generation (Heo, 2015; Muller, 2014). Estimates of the social costs of conventional and alternative-fueled vehicles emphasize the importance of the vehicle use phase and particularly the fuel source in determining the severity of health effects, which may range from less than $\$ 0.01 / \mathrm{L}$ (from electric vehicles (EVs) using solar or wind power) to as much as \$0.56/L gasoline equivalent (from EVs using coal power) (Michalek et al., 2011; NRC, 2010; Small and Kazimi, 1995; Tessum et al., 2014).

In this study, we examine the life-cycle social costs of air pollution and climate change from operation of the non-tactical vehicle fleet at a U.S. military installation. The wide variety of fuel sources and alternative-fuel vehicles (AFVs) available create a large decision-making space for fleet managers and other decision-makers in the DoD attempting to balance financial costs with energy security and health concerns. Using total cost of ownership, life-cycle assessment, and social cost techniques, we develop and compare fuel and vehicle purchase scenarios on the basis of financial viability, petroleum reduction, climate mitigation, and social costs of vehicle purchase and 
operation. Although the focus of our case study is on a single military installation, the insights gained are relevant to any organization, in both public and private sectors, with a large vehicle fleet.

\section{Methods}

\subsection{Vehicle fleet and fuel use data}

The non-tactical vehicle fleet inventory for Wright-Patterson Air Force Base as of July 11, 2014, and total fuel purchases from September 26, 2014, to October 4, 2015, were provided by site staff. Vehicles were categorized by gross vehicle weight (GVW) into light duty (under $4545 \mathrm{~kg}$ or 10,000 lbs GVW) and heavy duty (4545 kg and above GVW) and into eight subtypes by vehicle function (Table 1). We matched individual vehicles with fuel purchases to construct a database of annual fuel use by vehicle type. Only vehicle categories which aligned well with conventional commuting, travel, and hauling profiles were selected for further analysis; this will help other vehicle fleet managers recognize the broad applicability of the insights gained from our study. The remaining vehicle subcategories, including aerospace ground vehicles, construction, maintenance, and miscellaneous vehicles, were excluded to avoid misrepresentation of vehicle cost and fuel efficiency and due to insufficient data availability. The selected vehicles thus make up $83 \%$ of light duty vehicles and $55 \%$ of heavy duty vehicles at the installation.

Of the 540 vehicles included in the fuel purchase database, 247 were fuelled with E85, 112 used a conventional E10 gasoline blend, 37 used conventional diesel fuel, 118 used a low biodiesel blend (B20), and 26 were all-electric vehicles. According to site records, each vehicle received only one fuel type. The distribution of vehicle fuel types at the study site (one of the largest US Air Force installations) closely resembles the average DOD non-tactical fleet. According to U.S. Department of Energy data on DOD non-tactical vehicles, over $40 \%$ are E85-capable flex-fuel vehicles, about 40\% 
are conventional E10 and diesel fueled, and the rest are a combination of electric, hybrid, and natural gas vehicles (USDOE, 2015).

For the vehicle categories we selected, representative vehicles from the U.S. Federal Alternative Fuel Vehicle (AFV) Guide (GSA, 2015) were selected to generate a list of the lowest-cost vehicles for each type of fuel and functional category which would be available for purchase by the installation. The total fuel usage for each vehicle category was based on the total annual fuel use for all vehicles in that category at the installation. Annual vehicle mileage was based on the fuel use and the estimated fuel efficiency from similar vehicle models in the U.S. Federal AFV Guide. Alternative fuel prices are from The Office of Energy Efficiency \& Renewable Energy's April 2015 Clean Cities report (DOE, 2015). Gasoline and diesel prices are based on the Energy Information Administration (EIA) Weekly Price report for the U.S. Midwest, from January 5 to August 31, 2015 (EIA, 2015). To examine the effect of fuel price variability on total cost of ownership, we generated high and low fuel price values based on the maximum and minimum values for gasoline, diesel, natural gas, and electricity in the U.S. Energy Information Agency (EIA) quarterly price forecast for 2015-2016 (EIA, 2016). Low biofuel blends (E10, B20) were assigned price variability equal to that of gasoline and diesel, while high biofuel blends (E85, B100) and renewable electric power had double the price uncertainty of conventional fuels (table S2). We assume that ethanol blends using combined corn grain and stover feedstocks are available at the same price as conventional corn grain ethanol blends.

\subsection{Life-cycle air pollutant emissions}

We used two models from Argonne National Laboratory: the Alternative Fuel Life-cycle Environmental and Economic Transportation (AFLEET) model and the Greenhouse Gases, Regulated Emissions, and Energy Use in Transportation (GREET) model (http://greet.es.anl.gov). 
The models determine financial viability, air pollutant emissions, petroleum reduction, and climate mitigation outcomes for fuels and vehicle fleet scenarios. AFLEET generates total cost of ownership, life-cycle petroleum use, greenhouse gas emissions, and air pollutant emissions during vehicle use (Burnham, 2013). We supplemented these results with GREET data for air pollutant emissions during fuel production and for life-cycle petroleum use and greenhouse gas emissions for combined corn and corn stover ethanol, which is not modeled in AFLEET. A summary of various processes considered in the LCA is depicted in supplementary material (figure S1).

In addition to fuel types, we considered multiple feedstocks for ethanol production and electricity generation. Using GREET, we modeled ethanol produced from two facility types, corn grain and combined corn grain and stover. Although ethanol produced from perennial crops (e.g., switchgrass) may have lower greenhouse gas emissions, switchgrass ethanol is not widely available, whereas several large-scale combined corn grain and stover facilities are currently operating in the U.S. Electricity emissions for all-electric vehicles are calculated for current vehicles based on the ReliabilityFirst Corporation (RFC) regional electric mix. Alternative generation mixes include commercially available "green" power from local electric utilities, such as those offered by several utilities serving Ohio using wind, solar, and landfill gas. We model these services in GREET using a $20 \%$ biomass and $80 \%$ combined wind and solar electric mix and a $100 \%$ wind and solar scenario. GREET's inventory for fuel and energy production includes all life-cycle phases except for construction and maintenance of capital infrastructure, such as power plants, wind turbines, and solar panels. For liquid fuels and conventional electricity production, these are expected to contribute little more than 1 to $2 \%$ to total life-cycle emissions (Dunn et al., 2011; Wang et al., 2011). Though infrastructure may represent a higher proportion of life-cycle impacts for some renewable technologies, low-capital options are available as well (Asdrubali et al., 2015; Hertwich et al., 2015). 
To explore the uncertainty in fuel life-cycle emissions, we used the GREET stochastic toolkit to examine likely ranges of emissions from each fuel (Subramanyan et al., 2008). Using the built-in uncertainty distributions we ran 1000 model iterations using a Hammersley Sequence quasirandom sampling algorithm. Though not random, Hammersley Sequence sampling has the advantage of guaranteeing a wide coverage of the sample space with relatively few iterations (Kroese et al., 2011).

\subsection{Social cost of criteria air pollutants}

We combined spatially explicit emissions quantity and social costs data to allocate emissions from feedstock production, materials extraction, fuel production, and other upstream processes to their likely sources at the county scale. Social costs associated with air pollutants emitted during petroleum upstream processes and vehicle production were obtained from Michalek et al. (2011), who combined spatially explicit exposure estimates to develop county-level valuations of air pollutant health and mortality impacts. To generate average social costs for petroleum fuel and vehicle production emissions in the United States, the authors weighted pollution costs by county based on census-reported industrial activity in relevant sectors. We followed a similar methodology to develop social costs of bio-based ethanol and diesel fuels, weighting counties by corn and soy production in 2012 (USDA, 2015) in combination with county-level marginal social cost valuation estimates from the Estimating Air Pollution Social Impacts Using Regression (EASIUR) model (http://barney.ce.cmu.edu/ jinhyok/easiur/) (Heo and Adams, 2016a,b). The marginal costs per ton modeled for each pollutant at each life cycle stage are shown in table S1.

The EASUR model uses meteorological data from 2005 and sampling from data produced by the Comprehensive Air Quality Model with extensions (CAMx) to determine the fate of particulate 
emissions (Heo et al., 2016b; ENVIRON, 2012). The social cost of these emissions is estimated using epidemiological data on the effects of marginal increases in mortality and a value of statistical life (VSL) (Krewski et al., 2009). We selected EASIUR from the available models for estimating social cost of air pollutants because this tool provides the benefits of rigorous chemical transport models, such as improved modeling of secondary particulate formation, which are lacking in other models with equivalently low computational requirements. Since EASIUR does not account for secondary organic aerosols (SOA) from VOCs, we include a sensitivity analysis of our calculations to additional fuel-specific particulate matter $\left(\mathrm{PM}_{2.5}\right)$ formation rates as a function of VOC emissions (Gentner et al., 2012). Marginal CO damages, also excluded from EASIUR, are valued proportionally with PM2.5 damages from EASIUR, based on data from Michalek et al. (2011). Because the majority of emissions costs used in this study originate from the EASIUR model, we apply an average of the seasonal EASIUR sub-regional air quality modeling uncertainty multipliers to generate high and low marginal valuation estimates for nitrous oxides (NOx), PM, and sulfur dioxides (SOx) (table S2) (Heo et al., 2016).

We valued vehicle use phase emissions using the EASIUR model results for the zip code of the installation. The target year of our analysis is 2015. Though marginal social costs of pollution change over time, we chose a current-year approach which allowed us to take advantage of the best available data for recent and near-term estimations of emissions rates, pollution damages, and social costs of carbon. All social cost estimates were converted to a common value of statistical life (VSL) basis, which was $\$ 8,700,000$ in 2015 dollars (EPA, 2010a). Unless otherwise stated, monetary values are expressed in year 2015 dollars. Data for social costs of vehicle production, including batteries, were obtained from Michalek et al. (2011). We adjusted vehicle production costs to reflect the proportion of the vehicle lifetime spent at the installation using the vehicle depreciation 
(calculated in AFLEET). Battery production costs for hybrid, plug-in hybrid, and all-electric vehicles were also adjusted based on the expected range of the vehicle models identified in the U.S. Federal AFV Guide (GSA, 2015) using methods from Michalek et al. (2011). Social costs of air pollution during electricity production were taken from the National Resource Council (NRC, 2010).

\subsection{Social cost of greenhouse gas emissions}

We also assess the cost of climate change due to greenhouse gas (GHG) emissions. There is a wide range in suggested values for the social cost of GHG emissions (NRC, 2010; Tol, 2008), due to a combination of uncertainty regarding climate sensitivity to greenhouse gases (Roe and Baker, 2007), health and economic impacts of climate change (Pindyck, 2013; Tol, 2008) and selection of an appropriate discount rate (NRC, 2010; Tol, 2008). Our results are based on a cost of $\$ 44$ per metric ton of $\mathrm{CO}_{2}$-equivalent emissions, a central estimate of the U.S. Interagency Working Group on Social Cost of Carbon (IWGSCC, 2013). Of the many estimates available, this mid-range estimate was selected on the basis of both the potential real impacts of climate change on human health and the value ascribed to GHG reductions in U.S. public policy. We use alternative values from IWGSCC to examine the influence of uncertainty in the social cost of carbon on our results (table S2) (IWGSCC, 2013).

Estimating the carbon impact of biofuels invites many challenges, including accounting for the impact of food and fuel market effects such as indirect land use change and fuel market rebound. To assess the influence of market effects on the social costs of biofuels, we include estimates of additional greenhouse gas emissions due to land use change for corn grain ethanol (24 gCO2e/MJ) and soybean biodiesel production (25 gCO2e/MJ) (Plevin et al, 2015). Based on a study of the effects of a biofuel mandate on the U.S. fuel market, we estimate a 14\% rebound in petroleum use for renewable liquid fuels (Chen and Khanna, 2012). We model the rebound effect by attributing 
$14 \%$ of greenhouse gas and criteria air emissions from conventional fuels to renewable fuels on an energy basis. Due to the highly uncertain nature of market effect estimates, we include these values in our sensitivity analyses, rather than in our baseline results.

\subsection{Fuel and vehicle scenario development}

We assessed the life-cycle emissions and social costs of fuel and vehicle purchase decisions at Wright-Patterson Air Force Base in several scenarios. An alternative fuel purchase scenario was generated by selecting domestically-produced fuels with the lowest social costs within four categories (drop-in gasoline replacement, high-ethanol blends, drop-in diesel replacement, and electricity).

We examined the financial and social costs of purchasing, fueling, and maintaining conventional and alternative fueled vehicle fleets at the installation. As with the fuel purchasing scenario, we assume that decision-makers are limited to vehicle and fuel types which are produced domestically and must maintain the current number of vehicles in each functional category. We develop three alternative scenarios in which vehicle purchases are based on (A) minimizing social costs due to air pollution, (B) maximizing social return-on-investment (ROI) of alternative vehicle and fuel purchases (defined as the ratio of the difference in lifetime social costs between alternative-fueled vehicles and conventional gasoline or diesel fueled vehicles and the difference in lifetime financial costs), and (C) minimizing total combined financial and social costs.

\section{Results and discussion}

\subsection{Life-cycle air pollutant emissions of fuels}

We find that life-cycle non-GHG air pollutant emissions, particularly $\mathrm{NO}_{\mathrm{x}}$ and $\mathrm{PM}$, are higher for corn ethanol and other biofuel blends than conventional petroleum fuels. Emissions of volatile 
organic compounds (VOCs) and carbon monoxide (CO) increase by 9-50\% per $100 \mathrm{~km}$ traveled for high-ethanol blends from corn grain and combined grain and stover feedstocks. $\mathrm{NO}_{\mathrm{X}}, \mathrm{PM}$, and $\mathrm{SO}_{\mathrm{X}}$ increase by $71-124 \%$ from corn grain and $56-110 \%$ from combined grain and stover, relative to conventional gasoline. Biodiesel blends show an increase of 1-11\% (B20) and 4-55\% (B100) in air pollution, with the largest increases in $\mathrm{VOC}$ and $\mathrm{SO}_{\mathrm{x}}$ emissions. Electric vehicles show significant tradeoffs in emissions compared to liquid fuels. Of the three electric generation mixes modeled in this study, all result in large reductions (87-100\%) in life-cycle VOC and CO emissions relative to gasoline but increases of $150-500 \%$ in PM (RFC and "green" generation mixes) and $\mathrm{SO}_{\mathrm{x}}(\mathrm{RFC}$ mix) per $100 \mathrm{~km}$ vehicle use. Of all fuel sources studied, only electricity from solar and wind resulted in emissions reductions (65-100\%) in every category.

While all of the alternative fuels modeled reduce life-cycle greenhouse gas emissions relative to conventional petroleum, there remains a wide range in GHG reductions. E85 blends of ethanol from corn grain and combined corn grain and stover reduce emissions by $24-38 \%$, respectively, relative to gasoline. Biodiesel may be more effective, reducing GHGs by up to $78 \%$ versus diesel per $100 \mathrm{~km}$ traveled. Electric vehicles may more reliably reduce greenhouse gas emissions, showing 41\%, 98\%, and 99\% GHG reductions from the RFC, "green," and wind/solar generation mixes, respectively (table 2).

In general, stochastic analysis of uncertainty in emissions from fuel production and use supports these findings (figure S2). VOC emissions from gasoline and ethanol blends are an exception, with GREET stochastic results predicting higher emissions from ethanol blends from combined corn and corn stover feedstocks than from corn alone, while our baseline model estimates slightly lower VOC emissions when corn stover is included. There are two likely explanations for this - first, the GREET stochastic tool uses a different parameter set than the baseline GREET model, thus causing some 
results to differ, particularly for cellulosic ethanol and other novel fuel pathways. Secondly, our baseline estimates include use phase emissions from the AFLEET model, rather than GREET, which has more finely tuned emissions values by vehicle type and location. Baseline values for pollutants which come primarily from the use phase may be more accurate for the case study presented here than the GREET stochastic tool, which generates an expected range of emissions for passenger vehicles in the United States.

\subsection{Social cost of fuels}

We used social costs to compare and aggregate the relative impacts of each pollutant. Greenhouse gas emissions are the largest single contributor to the social cost of most fuels. For gasoline, diesel, E10, and B20, greenhouse gases contribute $47-54 \%$ of the total life-cycle social cost of the fuel, or $\$ 3.50$ to $\$ 4.10$ per GJ ( $\$ 0.77$ to $\$ 1.00$ per $100 \mathrm{~km}$ ). Higher biofuel blends show proportionally lower GHG contributions of 34\% (E85) and 18\% (B100) for fuel social costs. However, these GHG reductions may come at a price. The total social costs of ethanol blends are higher than that of gasoline, due in part to higher life-cycle emissions of non-GHG pollutants and higher health and mortality costs per unit. Although the cost per ton of pollutants from soy biodiesel production are similar to those of corn and corn stover ethanol (table S1), total emissions of VOCs, PM, and $\mathrm{SO}_{\mathrm{x}}$ from soy production and processing are substantially lower than those from corn. As a result, biodiesel blends produce lower life-cycle social costs ( $\$ 7.50$ and $\$ 5.10 / \mathrm{GJ}$, or $\$ 1.70$ and $\$ 1.10 / 100$ $\mathrm{km}$, for B20 and B100, respectively) than corn ethanol or conventional diesel ( $\$ 8.00 / \mathrm{GJ}$ or $\$ 1.80 / 100 \mathrm{~km})$.

A sensitivity analysis of fuel life-cycle social costs to changes in the social cost of carbon, market effects of biofuel production, and marginal air pollution damages shows that the relative ranking of fuel social costs is robust (figure S3). Only a high social cost of carbon or low marginal cost of air 
pollution, for example, can make E85 competitive with gasoline. Biodiesel blends have a lower social cost than conventional diesel in all cases, though the difference is highly sensitive to the social cost of carbon and the inclusion of biofuel market effects. Fuel market rebound effects and indirect land use change emissions increase the total social costs of corn ethanol and soybean biodiesel by $\$ 0.42 / 100 \mathrm{~km}$ and $\$ 0.65 / 100 \mathrm{~km}$ for passenger vehicles (18\% and $57 \%$, respectively).

On an energy basis, the life-cycle social cost of air pollution from the RFC electric mix, $\$ 14.40 / \mathrm{GJ}$, is much higher than that of the liquid fuels examined, although the higher efficiency of electric motors reduces its impact on a mileage basis $(\$ 1.01 / 100 \mathrm{~km})$. GHGs and $\mathrm{SO}_{\mathrm{x}}$ emissions dominate the social cost of the RFC mix, which is predominantly coal-based. Our "green" generation mix provides an $82 \%$ reduction in social costs $(\$ 2.63 / \mathrm{GJ}$ or $\$ 0.18 / 100 \mathrm{~km})$. A mix of exclusively wind and solar electric sources could provide power with social costs of $\$ 0.83 / \mathrm{GJ}$ (or $\$ 0.06 / 100 \mathrm{~km}$ ). As with biodiesel blends, the reduction in social costs from renewable electric generation is highly robust to changes in emissions valuation, although the relative benefit is sensitive to the social cost of carbon (figure S3). In most cases, life-cycle social costs from vehicle fuels are equivalent to $35-45 \%$ of the financial cost. Exceptions include B100 biodiesel and electricity, which generate 17\% (B100), and $58 \%, 9 \%$, and 3\% (RFC, "green" and wind/solar electric mixes, respectively) of their financial costs in combined GHG and air pollution damages. Electric generation from renewable sources has the most potential for reducing externalities due to climate change and air pollution (by $\$ 12-14 / \mathrm{GJ}$ or $82-99 \%$ ) with relatively low increases in financial purchase price $(\$ 5.60 / \mathrm{GJ}$ or $\$ 0.02 / \mathrm{kWh}$ ).

Our assessed social costs fall within ranges found in the literature. Vehicle use-phase social costs of non-greenhouse gases for gasoline have been estimated at $\$ 2.81$ (NRC, 2010), \$3.80 (Tessum et al., 2014), and $\$ 2.88$ (Hill et al., 2009) per GJ (compared to $\$ 3.42$ in our study). Non-climate social costs for ethanol are consistently higher for corn ethanol at \$3.19 (NRC, 2010), \$10.02 (Tessum et al., 
2014), and $\$ 11.27$ (Hill et al., 2009) per GJ (compared to $\$ 6.35$ for E85 in our study), but may be lower for cellulosic ethanol ( $\$ 5.80 / \mathrm{G}$ ) for corn stover (Tessum et al., 2014 ) and $\$ 1.88 / \mathrm{GJ}$ for prairie biomass (Hill et al., 2009) compared to $\$ 5.29$ for combined corn grain and stover E85 in our study). Our results show a greater difference in non-climate health impacts between fuels than the NRC study, but a smaller range than reported by Hill et al. (2009) or Tessum et al. (2014). This may be due in part to different assumptions about ethanol production. We examined emissions from current corn ethanol production, while Hill et al. (2009) include an anticipated increase in corn production exclusively on cropland reserve program lands, thus leading to differences in the quantity and spatial distribution of emissions. More broadly, the range in results between models is not unexpected given differences in life-cycle inventory data, chemical transport model selection, health impact parameters, and economic valuation.

Two factors could play outsize roles in the high social costs of vehicle fuels in this study; the location of Wright-Patterson Air Force Base in western Ohio, and the inclusion of social costs from carbon monoxide emissions. Greene County, which contains most of the base, ranks high in marginal emissions costs for $\mathrm{PM}_{2.5}, \mathrm{SO}_{\mathrm{X}}$, and $\mathrm{NO}_{\mathrm{X}}$ (92nd, 88th, and 88th percentiles of U.S. counties, respectively) according to the EASIUR model. Since most life-cycle air pollutant emissions from fuels occur during the use phase, the marginal damages reported here may be higher than for fuel and vehicle use at other sites. However, many large domestic DoD facilities are located near dense urban areas which may also have above-average marginal damages from air pollution. Additionally, the substantial fraction of damages associated with greenhouse gas emissions is not location-dependent.

Vehicles emit a majority of U.S. CO pollution (EPA, 2008), and CO is by far the most prolific criteria pollutant by mass from the internal combustion engines modeled in this study. CO exposure is 
linked to cardiovascular disease and mortality (Samoli et al., 2007; Shah et al., 2015). However, the foundational studies for current social cost valuation of CO pollution are decades old (reviewed by Matthews \& Lave, 2000), and the EPA has historically been reticent to include CO in estimates of the health impacts of air pollution (EPA, 1999). Despite the likelihood of complex and conflicting effects of $\mathrm{CO}$ on human health, we have elected to include it in this case study because of growing evidence of an effect on cardiovascular mortality and the particularly high CO concentrations associated with on-road transportation (EPA, 2010b). Removing CO from our analyses would reduce non-GHG social costs of fuels by $30 \%$ (high-ethanol blends) to $40 \%$ (gasoline and biodiesel).

\subsection{Fuel purchase scenarios}

We assessed the financial and health-based social costs of current fuel purchasing at the installation and compared the results with potential purchases of currently available, domestically-produced low-carbon alternative fuels. Wright-Patterson Air Force Base currently purchases predominantly diesel and biodiesel fuels, followed by high-ethanol blends, conventional low-ethanol blended gasoline, and electricity (Table 3). Purchasing the domestically-produced fuel in each category with the lowest social cost leads to a scenario in which biofuel blends and renewable electricity utilization are maximized. Total fuel purchase costs increase by $26 \%(\$ 56,000)$ primarily due to the higher cost of biodiesel. However, social costs of air pollution decrease by $34 \%(\$ 28,000)$. These health cost savings are based on a $63 \%$ reduction in greenhouse gas emissions, $37 \%$ reduction in $\mathrm{SO}_{2}$ (from 0.7 to $0.4 \mathrm{Mg} / \mathrm{yr}$ ), and $13 \%$ reduction in $\mathrm{NO}_{\mathrm{x}}$ emissions (from 1.1 to $1.0 \mathrm{Mg} / \mathrm{yr}$ ). Other pollutant emissions increased in the renewable fuel scenario: $38 \%$ for $\mathrm{PM}_{2.5}, 23 \%$ for $\mathrm{PM}_{10}$, and $14 \%$ for VOCs. These increases come primarily from increased soy biodiesel production, despite a large reduction in GHG emissions relative to conventional diesel. This scenario requires no change in vehicle purchasing, but instead focuses on reducing the health and climate effects of the existing vehicle fleet and acquisitions system by supplying fuels which meet the same engine requirements 
with lower life-cycle air pollutant emissions. Considering only the benefit from reducing GHG emissions, the financial cost of the renewable fuel purchases can be considered a carbon reduction cost of $\$ 99$ per ton of $\mathrm{CO}_{2}$.

Reducing petroleum dependency is a primary goal of U.S. alternative fuel policies, particularly in the armed forces (Blakeley, 2012a; Kendall, 2013). Although we do not include a valuation of the benefits of reducing petroleum consumption in our assessment of health-related cost externalities, many of the fuel scenarios presented here do result in substantial petroleum reductions. Others have estimated the economic value of reduced petroleum consumption or U.S. oil security premium at $\$ 0.006 / \mathrm{L}$ to $\$ 0.031 / \mathrm{L}$ (Brown and Huntington, 2013; Michalek et al., 2011). A 77\% reduction in life-cycle petroleum use, as in the alternative fuel scenario presented in Table 3, would represent a social cost savings ranging from $\$ 1,100$ to $\$ 6,100$, which represents $2-11 \%$ of the final social cost of fuel use in our alternative fuels scenario. With current oil prices at one-half to one-third the value at the time of these estimates, these values are likely an overestimate of current oil premiums. Considering the role of biofuel market effects could have a substantial impact on total petroleum consumption, however. Due to the increase in biodiesel (B100) consumption the alternative fuel scenario, a $14 \%$ fuel rebound effect would represent an additional 24,000 L of petroleum, $11 \%$ of current annual consumption at Wright-Patterson Air Force Base.

\subsection{Vehicle purchase scenarios}

The social and financial costs of operating alternative vehicle-fuel combinations can vary widely (Table S3). Minimizing the externalized social costs of fuel use (scenario A) results in purchases of all-electric vehicles and biodiesel fuels, thereby reducing total fleet air pollutant costs by $61 \%$ (Table 4). Lifetime financial costs of passenger cars drop from $\$ 61,000$ to $\$ 55,000$ per vehicle with the purchase of EV sedans but increase for all other vehicle types, with a total spending increase of 
$21 \%(\$ 5,700,000)$, primarily due to the high purchase price of all-electric short-haul cargo vans. Total fuel costs also increase by $10 \%(\$ 310,000)$ due to the higher purchase cost of B100. Life-cycle air emissions from "green" electric generation mixes from regional utilities are sufficiently low that electric vehicles provide the lowest social cost in all cases where they are available (Table S3). Electricity and B100 remain the lowest-social-cost fuels under all sensitivity analysis conditions.

Maximizing the effectiveness of financial investment in vehicles and fuels based on reduced air pollutant impacts (scenario B) results in a varied vehicle fleet including both B20 and B100 blends and LNG-fueled heavy-duty vans (Table 4). While EV sedans have an already-low lifetime financial cost , other vehicle types require a financial investment to reduce emissions. LNG-fueled vans, which reduce $\mathrm{GHG}, \mathrm{NO}_{\mathrm{X}}$, and $\mathrm{SO}_{\mathrm{X}}$ relative to the current fleet of predominantly gasoline and $\mathrm{E} 85$ vehicles, result in a $22 \%$ social ROI, while B20-fueled passenger and heavy trucks come closer to breaking even at $77 \%$ and $71 \%$ social ROI, respectively. In mid-sized trucks, B100 is more effective than B20 ( $56 \%$ vs $27 \%$ social ROI). Lifetime fleet social costs thus decrease $39 \%$ to $\$ 730,000$ while total fleet cost of ownership increases $10 \%$, including a $\$ 130,000$ increase in fuel costs.

The selection of EVs and biodiesel (either B20 or B100 blends) for most Scenario B vehicles is resilient to changing emissions valuation, biofuel market effects, vehicle use rates and fuel costs. In the delivery step van category, for which diesel engines are unavailable and electric motors are particularly expensive, LNG provides the highest social ROI under most conditions, although highethanol blends provide a higher return when social cost of carbon is high or VSL is low.

Minimizing total combined financial and social costs of the installation's vehicle fleet (scenario C) has mixed effects on vehicle and fuel purchases. Both lifetime financial and social costs are minimized by purchasing EV sedans powered by a "green" electric mix, but including the health 
effects of air pollution in cost considerations fails to overcome the affordability problem for other alternative fuels or vehicle types. Eliminating biodiesel purchases for heavy-duty trucks saves $\$ 15,000$ in lifetime fuel purchases at the cost of 345 additional tons of GHG emissions and $\$ 11,000$ in lifetime social costs. Overall, the effectiveness of both financial and social cost reductions from EV sedans powered by renewable electricity sources outweighs the social costs of increased gasoline and diesel purchases, resulting in fleet lifetime cost savings of $4.2 \%(\$ 1,100,000)$ and a $7.4 \%$ reduction in social costs of operation $(\$ 93,000)$.

Vehicle and fuel selections in scenario $\mathrm{C}$, as in scenarios A and B, are largely resilient to changes in sensitivity parameters. Only a high social cost of carbon leads to a change in vehicle selection in more than one vehicle category from the base scenario: E85 from combined corn \& stover feedstocks replaces low-ethanol (E10) gasoline for delivery step vans and biodiesel (B20) replaces diesel use in delivery straight trucks. Despite these results, an assessment of total combined social and financial costs emphasizes that changes to vehicle and fuel prices generally outweigh social cost parameters in determining the relative costs or benefits of alternative vehicle ownership at Wright-Patterson Air Force Base (Figure S4).

Despite its overall reduction in social costs, scenario C dramatically increases petroleum use $76 \%$ from 0.31 to 0.54 million L/yr (petroleum use is decreased by $61 \%$ and $90 \%$ in scenarios $\mathrm{A}$ and $\mathrm{B}$, respectively). Scenario C also increases total GHG emissions by 6\% (98 Mg/yr), while scenarios A and $\mathrm{B}$ reduce GHGs by 1,315 and $331 \mathrm{Mg} / \mathrm{yr}$, respectively, from the baseline of amount of 1,679 $\mathrm{Mg} / \mathrm{yr}$. Considering only the climate change impacts, the additional financial cost of scenario $\mathrm{A}$ provides reductions in GHG emissions at a cost of $\$ 629 / \mathrm{Mg}$. Because scenario B also provides a lower financial cost, a cost for emissions reductions cannot be calculated. 
For nearly all fuels, the largest single contributor to social costs is life-cycle GHG emissions. The lower emissions of alternative fuels can be examined in terms of the economic value of carbon required to reach purchase cost parity with conventional fuels. We find that $\mathrm{E} 10$ requires a $\mathrm{CO}_{2} \operatorname{cost}$ of $\$ 350$ and $\$ 322$ per metric ton to reach cost parity with pure gasoline when using ethanol from corn grain or combined grain and stover feedstocks, respectively. Biodiesel (B20) and E85 blends are much more cost-effective reductions in GHGs, reaching cost parity between $\$ 32$ and $\$ 78 / \mathrm{Mg}$ $\mathrm{CO}_{2}$ e. Pure biodiesel's high purchase price drives carbon parity costs somewhat higher, $\$ 136 / \mathrm{Mg}$ $\mathrm{CO}_{2}$ e. Offsetting the $\$ 0.02 / \mathrm{kWh}$ premium for renewable electricity credits would require a carbon price of $\$ 29 / \mathrm{Mg} \mathrm{CO}_{2} \mathrm{e}$ when used to power an electric sedan.

Our analysis focuses on the life-cycle impacts of the use phase of vehicle operation. Including the vehicle production stage could alter the prioritization of vehicle purchases in some of our scenarios, particularly the social cost return-on-investment due to the higher social costs of battery production for electric vehicles (Michalek et al., 2011). Unfortunately, insufficient data is available to incorporate vehicle and battery emissions for the many vehicle types in use at this installation. An assessment of the role of vehicle and battery production in sedans (Figure 3) shows that, at the high use rates and marginal emissions costs at the installation, the use phase remains the dominant factor in determining the social cost of vehicles. Including emissions costs from vehicle and battery production does not change the overall ranking of impacts from fuel and vehicle combinations. Because the DoD requires purchased vehicles to be manufactured in the U.S., these results are based on the spatial allocation of emissions to US automotive manufacturing counties. Vehicle production in other nations could have substantially different marginal emissions costs.

\section{Conclusion and Policy Implications}


We assessed the financial and social costs of fuel and vehicle policies at a large domestic DoD installation. Social costs of liquid fuels currently produced in the U.S. range from \$5.08-9.46 per GJ (\$0.18-0.29 per L), with $18-56 \%$ of these costs attributable to climate change and the remainder to health costs of air pollution. Our analysis shows that, from an economic perspective, including the social costs of vehicle operation is insufficient to drive changes in fuel purchasing or alternativefuel vehicle ownership. Similarly, policies which focus on a single endpoint, such as climate mitigation or energy security, may lead to a net increase in social costs of vehicle use. Notably, this conclusion appears robust across a wide range of uncertainty in emissions rates, marginal social costs, and market effects.

The reduction of petroleum consumption in the DoD has so far been accomplished in part by adoption of flex-fuel vehicles (FFVs) and E85 fuel using corn grain ethanol. Although high-ethanol blend fuels lower net petroleum consumption by over $70 \%$, our results support the conclusions of others that they may substantially increase health costs due to air pollution (Hill et al., 2009; NRC, 2010). DoD policymakers have asserted that alternative fuels for DoD operations must be derived from non-food crop feedstocks and be cost-competitive with conventional petroleum fuels (Blakeley, 2012a). Since current first-generation biofuels, corn ethanol and soy biodiesel, do not meet these requirements, electric vehicles may be more cost-effective and meet criteria for petroleum and GHG reductions while also reducing social costs from air pollution. Purchasing renewable or "green" electricity credits from regional utilities is the single case in our study in which the additional cost $(\$ 0.02 / \mathrm{kWh})$ is more than compensated for in reduced social costs $(\$ 0.04 / \mathrm{kWh})$.

Including the social cost of carbon in financial decision-making (i.e., applying a carbon tax of $\$ 44$ per metric ton of $\mathrm{CO}_{2}$ ) would tip the balance of cost-effectiveness for some renewable fuels, 
primarily soybean-based B20 and E85 using combined corn grain and stover ethanol (as well as electricity from both our "green" and renewable generation mixes). This could lead to increased biofuel adoption and reduced greenhouse gas emissions, while increasing social costs of air pollution in the United States. We find that climate change and air pollution reductions do not sufficiently overlap to focus exclusively on carbon when developing fuel policies. 


\section{Acknowledgments}

This research was supported by Defense Environmental Restoration Account (DERA) funds, and by an appointment to the Postgraduate Research Participation Program at the U.S. Air Force Institute of Technology (AFIT) administered by the Oak Ridge Institute for Science and Education through an interagency agreement between the U.S. Department of Energy and AFIT. We thank our anonymous reviewers for their helpful feedback.

\section{DISCLAIMER}

The views expressed in this paper are those of the authors and do not reflect the official policy or position of the U.S. Air Force, the DoD, or the U.S. government. 


\section{References}

Asdrubali, F., Baldinelli, G., D'Alessandro, F., Scrucca, F., 2015. Life cycle assessment of electricity production from renewable energies: Review and results harmonization. Renewable and Sustainable Energy Reviews 42, 1113-1122.

Blakeley, K., 2012. DOD Alternative Fuels: Policy, Initiatives and Legislative Activity, CRS Report for Congress. Congressional Research Service, Washington, DC.

Brinkman, N., Wang, M., Weber, T., Darlington, T., 2005. Well-to-wheels analysis of advanced fuel/vehicle systems - a North American study of energy use, greenhouse gas emissions, and criteria pollutant emissions. Argonne National Laboratory, Argonne, IL.

Brown, S.P.A., Huntington, H.G., 2013. Assessing the U.S. oil security premium. Energy Economics 38, 118-127.

Burnham, A., 2013. User Guide for AFLEET Tool 2013. Argonne National Laboratory, Lemont, IL, p. 27. Caiazzo, F., Ashok, A., Waitz, I.A., Yim, S.H.L., Barrett, S.R.H., 2013. Air pollution and early deaths in the United States. Part I: Quantifying the impact of major sectors in 2005. Atmospheric Environment 79, 198-208.

Chen, X., Khanna, M., 2012. The market-mediated effects of low carbon fuel policies. AgBioForum 15, 89-105.

Chester, M.V., Horvath, A., 2009. Environmental assessment of passenger transportation should include infrastructure and supply chains. Environmental Research Letters 4, 024008.

DOD, 2013. Sustainability Performance Report FY 2013, in: Kendall, F. (Ed.). US Department of Defense, Washington, DC, p. 84 . 
DOD, 2014. Integrating Sustainability into DoD Acquisitions, Department of Defense Guidance, 2.0 Draft ed. U.S. Department of Defense, p. 107.

DOE, 2015. Clean Cities Alternative Fuel Price Report. U.S. Department of Energy, Washington, DC, p. 18.

Dunn, J.B., Eason, J., Wang, M.Q., 2011. Updated sugarcane and switchgrass parameters in the GREET model. Argonne National Laboratory.

EIA, 2013. International Energy Outlook 2013, in: Conti, J., Holtberg, P., Beamon, J.A., Napolitano, S., Schaal, A.M., Turnure, J.T., Westfall, L. (Eds.). U.S. Energy Information Administration, Washington, DC, p. 312.

EIA, 2015. Gasoline and Diesel Fuel Update. U.S. Energy Information Administration, Washington, DC.

EIA, 2016. Short-Term Energy Outlook - August 2016. U.S. Energy Information Administration, Washington, DC.

EPA, 1999. The Benefits and Costs of the Clean Air Act 1990 to 2010, EPA Report to Congress. United States Environmental Protection Agency, Washington, DC.

EPA, 2008. National Emission Inventory Air Pollution Trends. United States Environmental Protection Agency, Washington, DC.

EPA, 2010a. Guidelines for Preparing Economic Analyses; National Center for Environmental Economics, Office of Policy, U.S. Environmental Protection Agency, Washington, D.C.

EPA, 2010b. Integrated Science Assessment for Carbon Monoxide. United States Environmental Protection Agency, Research Triangle Park, NC.

EPA, 2014. Profile of the 2011 National Air Emissions Inventory. US Environmental Protection Agency, Washington, DC.

ENVIRON, 2012. CAMx User's Guide Version 5.41. Environ International Corporation, Novato, CA. 
Exec. Order No. 13693, 3 C.F.R. 2015.

Gentner, D.R., Isaacman, G., Worton, D.R., Chan, A.W., Dallmann, T.R., Davis, L., Liu, S., Day, D.A., Russell, L.M., Wilson, K.R., Weber, R., Guha, A., Harley, R.A., Goldstein, A.H., 2012. Elucidating secondary organic aerosol from diesel and gasoline vehicles through detailed characterization of organic carbon emissions. Proc Natl Acad Sci U S A 109, 18318-18323.

GSA, 2015. 2015 Model Year Alternative Fuel Vehicle (AFV) Guide, in: Administration, U.S.G.S. (Ed.). U.S. General Services Administration, Washington, DC.

Hawkins, T.R., Singh, B., Majeau-Bettez, G., Strømman, A.H., 2013. Comparative Environmental Life Cycle Assessment of Conventional and Electric Vehicles. Journal of Industrial Ecology 17, 53-64.

Heo, J., 2015. Evaluation of Air Quality Impacts on Society: Methods and Application, Engineering and Public Policy. Carnegie Mellon University, Pittsburgh, PA.

Heo, J., Adams, P., 2015. EASIUR User's Guide Version 0.2, May, 2015.

http://barney.ce.cmu.edu/ jinhyok/easiur/ (accessed on 10.12.15).

Heo, J., Adams, P. J., Gao, H. O., 2016. Public Health Costs of Primary PM2.5 and Inorganic PM2.5 Precursor Emissions in the United States. Environ. Sci. Technol. 50, 6061-6070.

Heo, J., Adams, P.J., Gao, H.O., 2016. Reduced-form modeling of public health impacts of inorganic PM2.5 and precursor emissions. Atmospheric Environment, 137, 80-89.

Hertwich, E.G., Gibon, T., Bouman, E.A., Arvesen, A., Suh, S., Heath, G.A., Bergesen, J.D., Ramirez, A., Vega, M.I., Shi, L., 2015. Integrated life-cycle assessment of electricity-supply scenarios confirms global environmental benefit of low-carbon technologies. Proc Natl Acad Sci U S A 112, 6277-6282. 
Hill, J., Polasky, S., Nelson, E., Tilman, D., Huo, H., Ludwig, L., Neumann, J., Zheng, H., Bonta, D., 2009. Climate change and health costs of air emissions from biofuels and gasoline. Proc Natl Acad Sci U S A $106,2077-2082$.

IWGSCC, 2013. Technical Update of the Social Cost of Carbon for Regulatory Impact Analysis Under Executive Order 12866. Interagency Working Group on Social Cost of Carbon, United States Government, Washington DC, p. 21.

Kendall, F., 2013. Department of Defense Sustainability Performance Report FY 2013. Department of Defense, Washington, DC.

Krewski, D., Jerrett, M., Burnett, R.T., Ma, R., Hughes, E., Shi, Y., Turner, M.C., Pope, C.A., 3rd, Thurston, G., Calle, E.E., Thun, M.J., Beckerman, B., DeLuca, P., Finkelstein, N., Ito, K., Moore, D.K., Newbold, K.B., Ramsay, T., Ross, Z., Shin, H., Tempalski, B., 2009. Extended follow-up and spatial analysis of the American Cancer Society study linking particulate air pollution and mortality. No. Research report 140. Health Effects Institute, Boston, MA.

Kroese, D.P., Taimre, T., Botev, Z.I., 2011. Handbook of Monte Carlo Methods. John Wiley \& Sons, Inc., Hoboken, NJ.

Lepeule, J., Laden, F., Dockery, D., Schwartz, J., 2012. Chronic exposure to fine particles and mortality: an extended follow-up of the Harvard Six Cities study from 1974 to 2009. Environmental health perspectives 120, 965.

Matthews, H.S., Lave, L.B., 2000. Applications of Environmental Valuation for Determining Externality Costs. Environmental Science \& Technology 34, 1390-1395.

McCollum, D.L., Krey, V., Riahi, K., Kolp, P., Grubler, A., Makowski, M., Nakicenovic, N., 2013. Climate policies can help resolve energy security and air pollution challenges. Climatic Change 119, 479-494. 
Michalek, J.J., Chester, M., Jaramillo, P., Samaras, C., Shiau, C.S., Lave, L.B., 2011. Valuation of plug-in vehicle life-cycle air emissions and oil displacement benefits. Proc Natl Acad Sci U S A 108, 16554-16558.

Muller, N.Z., 2014. Boosting GDP growth by accounting for the environment. Science 345, 873-874.

NRC, 2010. Hidden Costs of Energy: Unpriced Consequences of Energy Production and Use. Committee on Health, Environmental, and Other External Costs and Benefits of Energy Production and Consumption; National Research Council, Washington, DC.

Pindyck, R.S., 2013. Climate Change Policy: What Do the Models Tell Us? Journal of Economic Literature $51,860-872$.

Plevin, R.J., Beckman, J., Golub, A.A., Witcover, J., O'Hare, M., 2015. Carbon accounting and economic model uncertainty of emissions from biofuels-induced land use change. Environ Sci Technol 49, 26562664.

Roe, G.H., Baker, M.B., 2007. Why is climate sensitivity so unpredictable? Science 318, 629-632.

Samoli, E., Touloumi, G., Schwartz, J., Anderson, H.R., Schindler, C., Forsberg, B., Vigotti, M.A., Vonk, J., Kosnik, M., Skorkovsky, J., Katsouyanni, K., 2007. Short-term effects of carbon monoxide on mortality: an analysis within the APHEA project. Environ Health Perspect 115, 1578-1583.

Shah, A.S., Lee, K.K., McAllister, D.A., Hunter, A., Nair, H., Whiteley, W., Langrish, J.P., Newby, D.E., Mills, N.L., 2015. Short term exposure to air pollution and stroke: systematic review and meta-analysis. BMJ $350,1-10$.

Small, K.A., Kazimi, C., 1995. On the Costs of Air Pollution from Motor Vehicles. Journal of Transport Economics \& Policy 29.

Subramanyan, K., Wu, Y., Diwekar, U.M., Wang, M.Q., 2008. New Stochastic Simulation Capability Applied to the GREET Model. International Journal of Life Cycle Assessment 13, 278-285. 
Tessum, C.W., Hill, J.D., Marshall, J.D., 2014. Life cycle air quality impacts of conventional and alternative light-duty transportation in the United States. Proc Natl Acad Sci U S A 111, 18490-18495.

Tol, R.S.J., 2008. The Social Cost of Carbon: Trends, Outliers and Catastrophes. Economics: The OpenAccess, Open-Assessment E-Journal 2, 1.

USDA, 2015. USDA-NASS QuickStats. http://www.nass.usda.gov/Quick_Stats/ (accessed Dec 10, 2015).

USDOE, 2015. http://federalfleets.energy.gov/performance_data (accessed Aug 15, 2016)

Wang, M., Han, J., Haq, Z., Tyner, W.E., Wu, M., Elgowainy, A., 2011. Energy and greenhouse gas emissions effects of corn and cellulosic ethanol with technology improvements and land use changes. Biomass and Bioenergy 35, 1885-1896. 


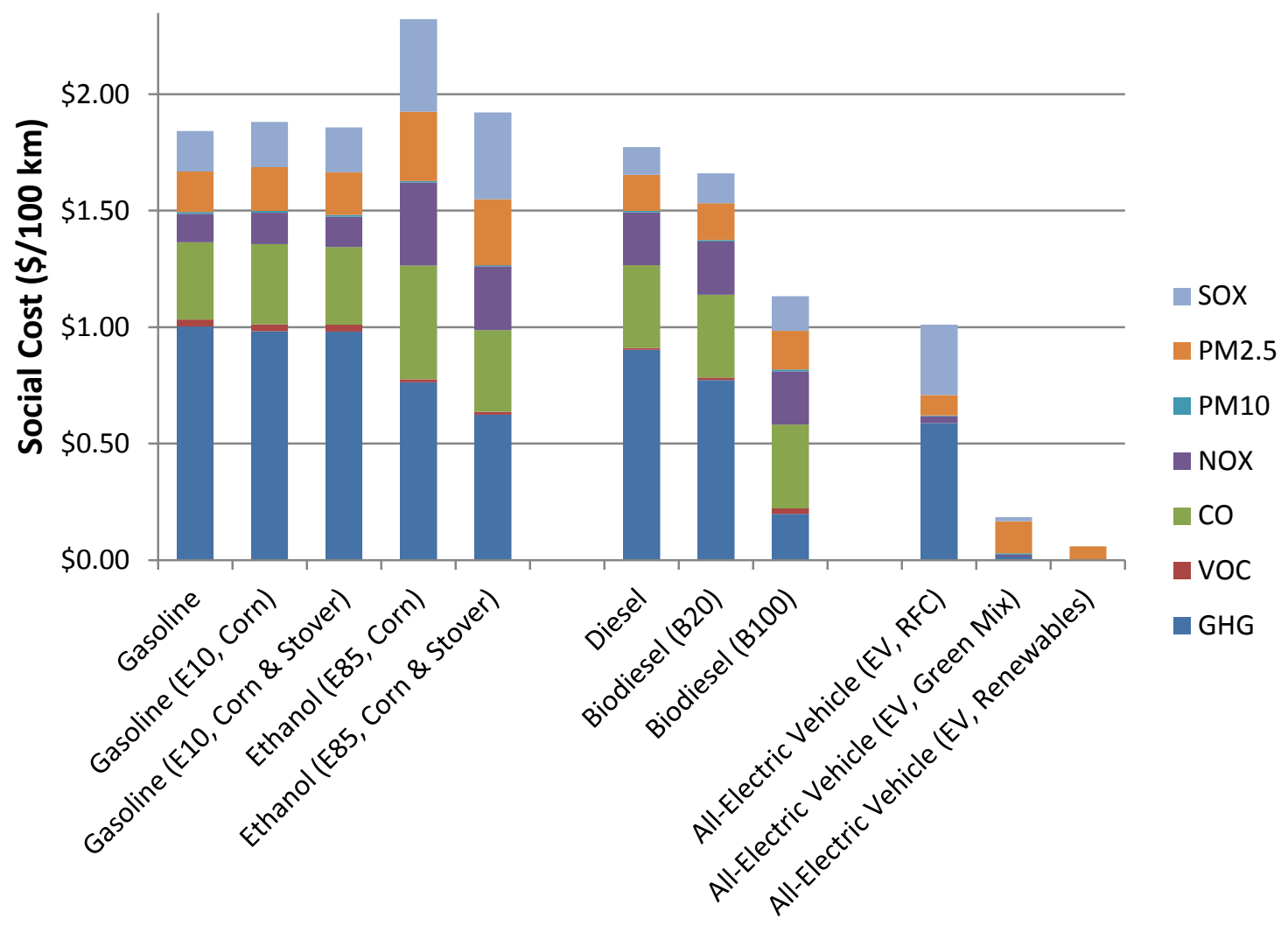

Fig. 1. Air pollutant contributions to life-cycle social cost of vehicle fuels used in light passenger cars. The electricity generation scenarios are: RFC, Reliability First Corporation, which manages the electric generation mix for the multi-state region including Ohio and WPAFB; 'Green Mix' a modeled electric generation mix of $20 \%$ biomass combustion and $80 \%$ combined wind and solar power, and; 'Renewables' a modeled electric generation mix of $100 \%$ combined wind and solar power. 


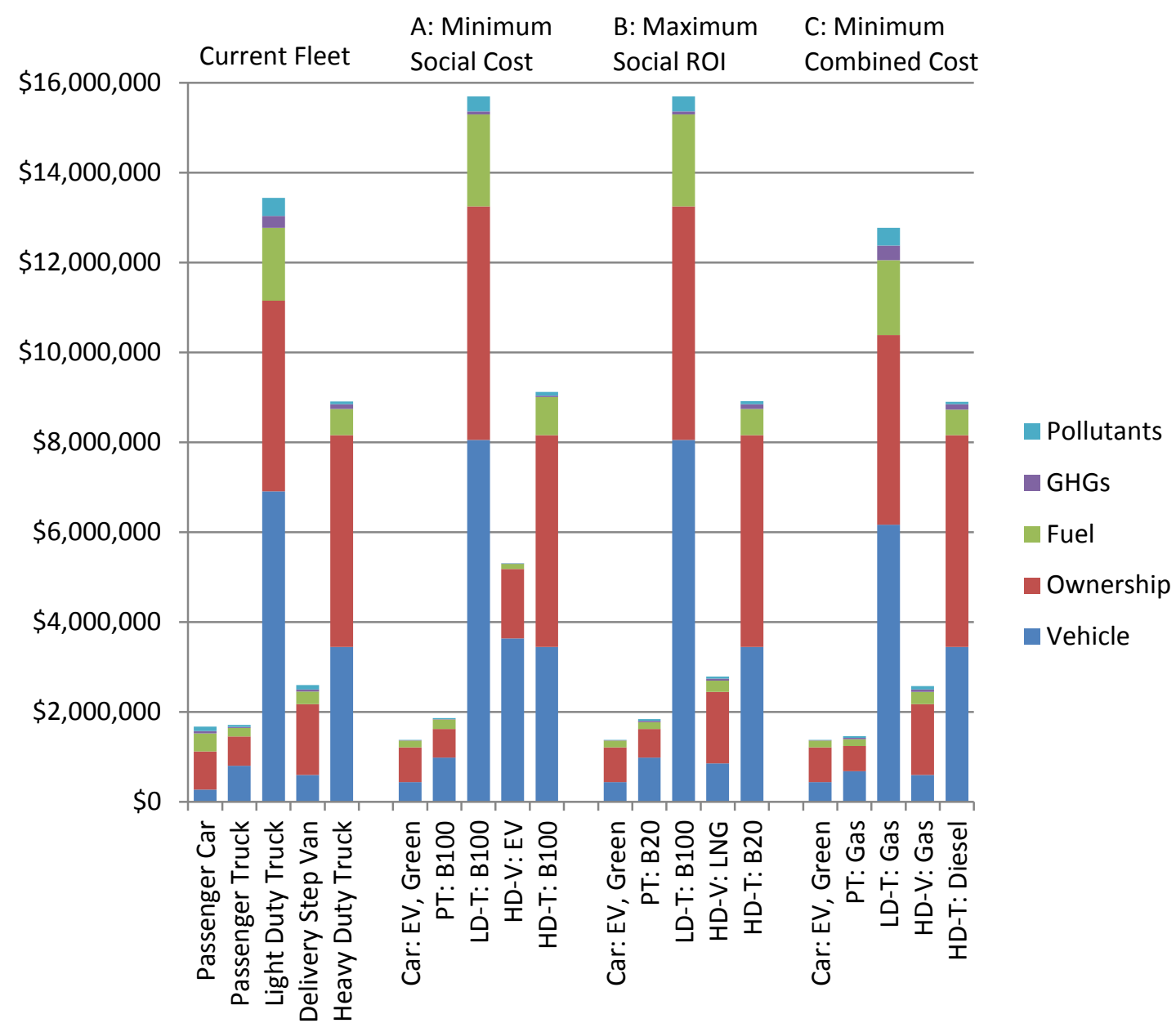

Fig. 2. Lifetime combined financial and social costs of current and potential vehicle fleets, by vehicle type. "Green" refers to "green" electric generation mix from local utilities. "Gas" refers to conventional E10 gasoline. LD-T: Light Duty Truck; HD-T: Heavy Duty Truck; HD-V: Delivery Step Van. 


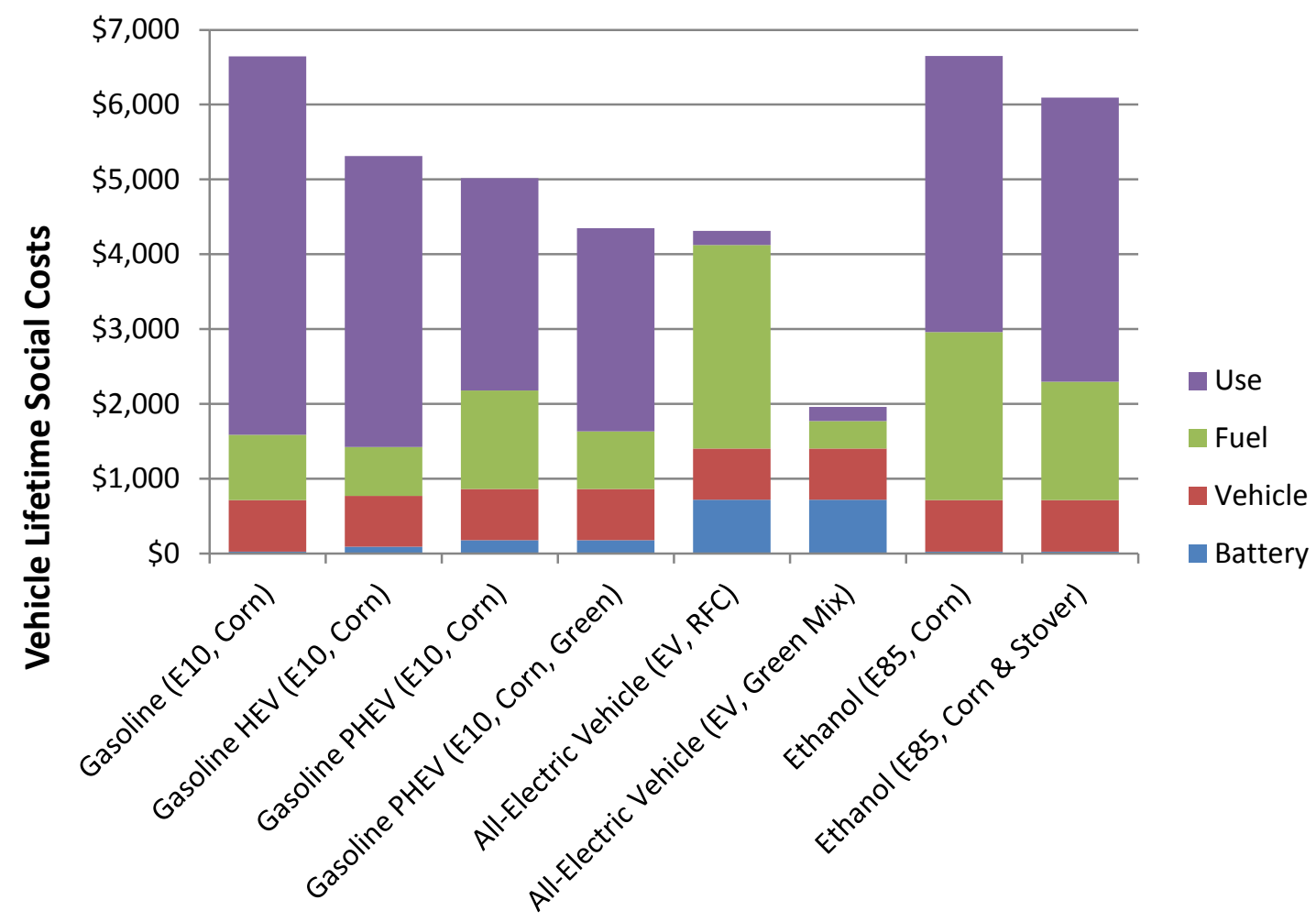

Fig. 3. Lifetime social costs of fuel-vehicle combinations for light sedans at the use rates seen at Wright Patterson Air Force Base. Components include battery and vehicle production, fuel production, and vehicle use (including fuel combustion). The electricity generation scenarios are: RFC, Reliability First Corporation, which manages the electric generation mix for the multi-state region including Ohio and WPAFB, and 'Green Mix' a modeled electric generation mix of $20 \%$ biomass combustion and $80 \%$, combined wind and solar power. 
Table 1: Categorization of vehicles at the installation and associated AFLEET model vehicle pathways.

\begin{tabular}{|c|c|c|c|}
\hline Vehicle Type & $\begin{array}{c}\text { Vehicle } \\
\text { Inventory at } \\
\text { WPAFB }\end{array}$ & $\begin{array}{c}\text { Corresponding AFLEET } \\
\text { Model Category }\end{array}$ & $\begin{array}{c}\text { Number of } \\
\text { Vehicles } \\
\text { Studied }\end{array}$ \\
\hline Light Duty (LD) & 529 & & 443 \\
\hline Car & 26 & Passenger car & 25 \\
\hline Passenger Truck / SUV & 56 & Passenger truck & 52 \\
\hline Van & 37 & light commercial truck & 366 \\
\hline Truck & 357 & Ligmi commercial lruck & 300 \\
\hline Aerospace Ground Vehicles & 12 & - & - \\
\hline Misc & 41 & - & \\
\hline Heavy Duty (HD) & 213 & & 97 \\
\hline Maintenance / Winter & 23 & - & - \\
\hline Construction & 5 & - & - \\
\hline \multirow{2}{*}{ Truck } & \multirow{2}{*}{105} & Delivery Step Van & 24 \\
\hline & & Delivery Straight Truck & 73 \\
\hline Aerospace Ground Vehicles & 35 & - & - \\
\hline Misc & 44 & - & - \\
\hline
\end{tabular}


Table 2: Life cycle inventory results for greenhouse gas and air pollutant emissions from fuels (g/100 km).

* Reliability First Corporation, which manages the electric generation mix for the multi-state region including Ohio and WPAFB

† A modeled electric generation mix of $20 \%$ biomass combustion and $80 \%$ combined wind and solar power

¥ A modeled electric generation mix of $100 \%$ combined wind and solar power

\begin{tabular}{l|ccccccc|} 
& $\mathbf{C O}_{\mathbf{2}} \mathbf{e}$ & $\mathbf{V O C}$ & $\mathbf{C O}$ & $\mathbf{N O}_{\mathbf{x}}$ & $\mathbf{P M}_{\mathbf{1 0}}$ & $\mathbf{P M}_{\mathbf{2 . 5}}$ & SO $_{\mathbf{x}}$ \\
\hline Gasoline & 23,000 & 15 & 147 & 17 & 2.2 & 1.4 & 9 \\
Gasoline (E10, Corn) & 22,500 & 16 & 153 & 19 & 2.5 & 1.5 & 10 \\
Gasoline (E10, Corn \& Stover) & 22,500 & 15 & 148 & 18 & 2.5 & 1.4 & 10 \\
Ethanol (E85, Corn) & 17,500 & 23 & 221 & 34 & 5.0 & 2.3 & 20 \\
Ethanol (E85, Corn \& Stover) & 14,300 & 21 & 160 & 27 & 4.7 & 2.1 & 19 \\
& & & & & & & \\
Diesel & 20,700 & 6 & 156 & 22 & 2.1 & 1.2 & 7 \\
Biodiesel (B20) & 17,700 & 7 & 158 & 22 & 2.2 & 1.2 & 7 \\
Biodiesel (B100) & 4,600 & 9 & 165 & 23 & 2.3 & 1.4 & 8 \\
Electric Vehicle (EV, RFC*) & & & & & & & \\
Electric Vehicle (EV, Green Mix $\left.{ }^{\dagger}\right)$ & 13,500 & 1 & 3 & 17 & 6.5 & 3.5 & 50 \\
Electric Vehicle (EV, Renewables $\neq)$ & 660 & 1 & 20 & 5 & 12.7 & 8.5 & 3 \\
& 67 & 0 & 0 & 0 & 0.9 & 0.2 & 0
\end{tabular}


Table 3: Financial and health costs of fuel purchases in conventional and renewable fuel scenarios

* Reliability First Corporation, which manages the electric generation mix for the multi-state region including Ohio and WPAFB

† A modeled electric generation mix of $20 \%$ biomass combustion and $80 \%$ combined wind and solar power

\begin{tabular}{llllll} 
Current Annual Fuel Purchase & L (or kWh) & Total Cost & Social Cost & Petroleum (L) & GHG (t) \\
\hline Gasoline (E10, Corn) & 38,600 & $\$ 24,800$ & $\$ 8,970$ & 32,900 & 107 \\
Ethanol (E85, Corn) & 59,800 & $\$ 30,300$ & $\$ 12,900$ & 11,400 & 97 \\
Diesel & 74,500 & $\$ 53,900$ & $\$ 21,400$ & 78,500 & 250 \\
Biodiesel (B20) & 128,000 & $\$ 94,200$ & $\$ 34,000$ & 109,000 & 362 \\
Electricity (RFC*) & 108,000 & $\$ 9,740$ & $\$ 5,620$ & 400 & 75 \\
\hline Total & & $\$ 213,000$ & $\$ 82,800$ & 232,000 & 890 \\
Alternative Fuel Scenario & & & & \\
Gasoline (E10, Corn \& Stover) & 38,600 & $\$ 24,800$ & $\$ 8,850$ & 32,900 & 107 \\
Ethanol (E85, Corn \& Stover) & 59,800 & $\$ 30,300$ & $\$ 10,700$ & 11,700 & 80 \\
Biodiesel (B100) & 203,000 & $\$ 202,000$ & $\$ 34,300$ & 8400 & 138 \\
Electricity (Green Mix $\dagger$ ) & 108,000 & $\$ 11,900$ & $\$ 1,030$ & 310 & 2 \\
\hline Total & & $\$ 269,000$ & $\$ 54,900$ & 53,300 & 327
\end{tabular}


Table 4: Financial and social costs of current and alternative vehicle fleets. Scenarios are (A) minimized social costs, (B) maximized social cost ROI, and (C) minimized combined social and financial costs.

* Reliability First Corporation, which manages the electric generation mix for the multi-state region including Ohio and WPAFB

† A modeled electric generation mix of $20 \%$ biomass combustion and $80 \%$ combined wind and solar power

Fuel (L or Total Cost of GHGs Petroleum

kWh)

\begin{tabular}{|c|c|c|c|c|c|c|}
\hline Current Fleet Total & & & $\$ 27,200,000$ & 1680 & 307,000 & $\$ 1,200,000$ \\
\hline \multirow[t]{3}{*}{ Passenger Car } & Gasoline (E10, Corn) & 4280 & $\$ 60,000$ & 2 & 640 & $\$ 1,100$ \\
\hline & Gasoline HEV (E10, Corn) & 4280 & $\$ 96,000$ & 2 & 640 & $\$ 1,160$ \\
\hline & Ethanol (E85, Corn) & 771,000 & $\$ 1,370,000$ & 200 & 18300 & $\$ 150,000$ \\
\hline \multirow[t]{4}{*}{ Passenger Truck } & Gasoline (E10, Corn) & 45,800 & $\$ 269,000$ & 22 & 6800 & $\$ 12,400$ \\
\hline & Diesel & 420 & $\$ 26,700$ & 0 & 79 & $\$ 130$ \\
\hline & Biodiesel (B20) & 2290 & $\$ 56,500$ & 1 & 334 & $\$ 700$ \\
\hline & Ethanol (E85, Corn) & 305000 & $\$ 1,290,000$ & 81 & 7230 & $\$ 56,700$ \\
\hline \multirow[t]{5}{*}{ Light Commercial Truck } & Gasoline (E10, Corn) & 822,000 & $\$ 3,080,000$ & 400 & 121,000 & $\$ 204,000$ \\
\hline & Diesel & 7950 & $\$ 479,000$ & 5 & 1430 & $\$ 2,350$ \\
\hline & $\mathrm{EV}\left(\mathrm{RFC}^{*}\right)$ & 634,000 & $\$ 1,160,000$ & 72 & 400 & $\$ 32,700$ \\
\hline & Biodiesel (B20) & 73,300 & $\$ 1,970,000$ & 35 & 10,500 & $\$ 19,800$ \\
\hline & Ethanol (E85, Corn) & $1,920,000$ & $\$ 6,080,000$ & 510 & 45,600 & $\$ 411,000$ \\
\hline \multirow[t]{2}{*}{ Delivery Step Van } & Gasoline (E10, Corn) & 208,000 & $\$ 1,050,000$ & 61 & 18,600 & $\$ 64,900$ \\
\hline & Ethanol (E85, Corn) & 293,000 & $\$ 1,410,000$ & 47 & 4200 & $\$ 78,900$ \\
\hline \multirow[t]{2}{*}{ Delivery Straight Truck } & Diesel & 128,000 & $\$ 2,300,000$ & 44 & 13700 & $\$ 28,800$ \\
\hline & Biodiesel (B20) & 667,000 & $\$ 6,450,000$ & 193 & 57300 & $\$ 137,000$ \\
\hline Scenario A & & & $\$ 32,800,000$ & 364 & 29,700 & $\$ 573,000$ \\
\hline Passenger Car & EV (Green Mix ${ }^{\dagger}$ ) & $1,410,000$ & $\$ 1,370,000$ & 5 & 715 & $\$ 15,200$ \\
\hline Passenger Truck & Biodiesel (B100) & 210,000 & $\$ 1,830,000$ & 27 & 2180 & $\$ 29,200$ \\
\hline Light Commercial Truck & Biodiesel (B100) & $2,060,000$ & $\$ 15,300,000$ & 265 & 21,300 & $\$ 400,000$ \\
\hline Delivery Step Van & EV (Green Mix ${ }^{\dagger}$ ) & $4,040,000$ & $\$ 5,300,000$ & 2 & 334 & $\$ 10,100$ \\
\hline Delivery Straight Truck & Biodiesel (B100) & 850,000 & $\$ 9,010,000$ & 65 & 5,260 & $\$ 118,000$ \\
\hline Scenario B & & & $\$ 30,100,000$ & 537 & 57,700 & $\$ 737,000$ \\
\hline Passenger Car & EV (Green Mix ${ }^{\dagger}$ ) & $1,410,000$ & $\$ 1,370,000$ & 5 & 715 & $\$ 15,200$ \\
\hline Passenger Truck & Biodiesel (B20) & 209,000 & $\$ 1,770,000$ & 101 & 30,000 & $\$ 64,800$ \\
\hline Light Commercial Truck & Biodiesel (B100) & $2,060,000$ & $\$ 15,300,000$ & 265 & 21,300 & $\$ 400,000$ \\
\hline Delivery Step Van & LNG & 626,000 & $\$ 2,700,000$ & 101 & 445 & $\$ 87,600$ \\
\hline Delivery Straight Truck & Biodiesel (B20) & 797,000 & $\$ 8,750,000$ & 65 & 5,260 & $\$ 169,000$ \\
\hline Scenario C & & & $\$ 26,050,000$ & 1,776 & 541,000 & $\$ 1,110,000$ \\
\hline Passenger Car & EV (Green Mix ${ }^{\dagger}$ ) & $1,410,000$ & $\$ 1,370,000$ & 5 & 715 & $\$ 15,200$ \\
\hline Passenger Truck & Gasoline (E10, Corn) & 235,000 & $\$ 1,400,000$ & 114 & 34,700 & $\$ 66,200$ \\
\hline Light Commercial Truck & Gasoline (E10, Corn) & $2,600,000$ & $\$ 12,100,000$ & 1,260 & 383,000 & $\$ 718,000$ \\
\hline Delivery Step Van & Gasoline (E10, Corn) & 424,000 & $\$ 2,450,000$ & 125 & 37,800 & $\$ 132,000$ \\
\hline Delivery Straight Truck & Diesel & 785,000 & $\$ 8,730,000$ & 272 & 84,200 & $\$ 177,000$ \\
\hline
\end{tabular}

